\title{
Os sujeitos endividados e a Educação Financeira
}

\section{Indebted subjects and Financial Education}

\author{
Karla Schuck Saraiva*
}

\begin{abstract}
RESUMO
O artigo analisa as propostas de Educação Financeira de três países - Estados Unidos, França e Brasil -, baseadas no uso de sites, visando compreender suas orientações e objetivos. As análises mostram que o site norte-americano é orientado para tornar os sujeitos individualmente responsáveis por suas escolhas e decisões financeiras, enquanto o site francês procura mostrar de modo mais amplo o funcionamento das finanças e da economia. O site brasileiro tem um modelo de Educação Financeira semelhante ao norte-americano. O trabalho é finalizado com sugestões para reorganizar a proposta brasileira.
\end{abstract}

Palavras-chave: Educação Financeira. Biopolítica. Neoliberalismo.

\begin{abstract}
The paper analyzes the proposals of Financial Education of three countries - the United States of America, France and Brazil -, based on the use of sites, aiming to understand its predispositions and objectives. Analyses show that the American site is geared towards making subjects individually responsible for their financial choices and decisions, while the French site seeks to show the functioning of finance and the economy in a broader sense. The Brazilian site has a Financial Education model similar to the American one. The conclusion of this article brings suggestions to reorganize the Brazilian proposal.
\end{abstract}

Keywords: Financial Education. Biopolitics. Neoliberalism.

DOI: $10.1590 / 0104-4060.53867$

* Universidade Luterana do Brasil. Programa de Pós-Graduação em Educação. Canoas, Rio Grande do Sul, Brasil. Avenida Farroupilha, nº 8001. Bairro São José. CEP 92425-900. E-mail: karlasaraiva@via-rs.net 


\begin{abstract}
Todos são "devedores", culpados e responsáveis, frente ao capital que se manifesta como o Grande Credor, o Credor universal.
\end{abstract}

Maurizio Lazzarato

Desde o início do século XXI, é possível observar um movimento internacional de fortalecimento daquilo que vem sendo chamado de Educação Financeira. Em especial, é importante destacar o papel proeminente da Organização para a Cooperação e Desenvolvimento Econômico (OCDE). Desde 2003, esta instituição vem atuando junto a diversos países no intuito de promover iniciativas voltadas para a implantação da Educação Financeira. Em 2008, no auge da crise financeira internacional, conhecida como a crise do subprime ${ }^{1}$, a OCDE criou a Rede Internacional de Educação Financeira (INFE) para integrar as experiências internacionais (INFE, 2017). O destaque dado pela OECD para estas práticas estaria relacionado com a necessidade de regular mercados altamente desregulados. "A implicação, a mobilização subjetiva e o trabalho sobre si, defendidos pela gestão desde os anos 1980, metamorfosearam-se em uma injunção para tomar para si os custos e os riscos da catástrofe econômica e financeira" (LAZZARATO, 2011, p. 12).

A OCDE, avançando rumo ao seu objetivo de disseminar a Educação Financeira, insere, a partir de 2012, no PISA², que até então era baseado na avaliação de três áreas - Leitura, Matemática e Ciências -, uma prova de Educação Financeira. Segundo a publicação Aperfeiçoando a educação financeira (OECD, 2005),

Educação Financeira é o processo pelo qual consumidores/investidores aperfeiçoam seu entendimento dos produtos e conceitos financeiros e, por meio de informação, instrução e conselhos objetivos, desenvolvem habilidades e confiança para tornarem-se mais conscientes dos riscos e das oportunidades financeiras, para tomarem decisões com base em informações, para saber onde buscar ajuda e para realizar outras ações efetivas para melhorar seu bem-estar financeiro.

1 “A crise do subprime é uma crise financeira desencadeada em 24 de julho de 2007, a partir da queda do índice Dow Jones, motivada pela concessão de empréstimos hipotecários de alto risco, prática que arrastou vários bancos para uma situação de insolvência, repercutindo fortemente sobre as bolsas de valores de todo o mundo". (WIKIPEDIA, 2017).

2 O Programa Internacional para Avaliação de Estudantes (PISA) constitui-se em uma pesquisa trianual, organizada pela OCDE, que pretende avaliar os sistemas de educação ao redor do mundo por meio da testagem das habilidades e conhecimentos de alunos de 15 anos de idade. (OECD, 2017b). 
Além disso, no site da organização consta que "A Educação Financeira tornou-se um importante complemento da conduta do mercado e da regulamentação prudencial e melhorou os comportamentos financeiros individuais, uma prioridade política de longo prazo em muitos países" (OECD, 2017a). Os dois excertos acima sinalizam uma preocupação de conduzir as condutas dos indivíduos, de modo a torná-los prudentes no trato com o dinheiro e capazes de assumir a responsabilidade de gerir suas finanças com autonomia, mesmo nas situações mais adversas. Essas habilidades, segundo a OCDE, repercutiriam tanto em seu bem-estar quanto no bom funcionamento dos mercados. Isso fica particularmente claro em outro documento que analisa o PISA 2012:

\begin{abstract}
Boas habilidades de letramento financeiro permitiriam que os indivíduos tomassem decisões mais bem informadas em um mercado financeiro cada vez mais complexo e que, por sua vez, essas decisões bem informadas poderiam ter repercussões positivas nos mercados financeiros e na economia como um todo (OECD, 2013, p. 141).
\end{abstract}

Frente a esse cenário, observa-se que cresce o número de iniciativas nacionais para mobilizar estratégias de Educação Financeira não apenas junto às escolas, mas também com vistas a atingir um público mais amplo por meio de ações que não estejam ligadas às instituições de educação formal. O objetivo deste artigo é analisar as propostas de Educação Financeira de três países - Estados Unidos, França e Brasil - baseadas no uso de sites, visando compreender suas orientações e objetivos. Neste caso, os sites são assumidos pelas próprias instituições responsáveis pelas estratégias nacionais de Educação Financeira como artefatos pedagógicos a serem utilizados para moldar condutas financeiras $^{3}$. Como irei mostrar ao longo do artigo, os sites dos Estados Unidos e da França apresentam orientações sobre Educação Financeira um tanto diferentes entre si, sendo que o brasileiro se aproxima mais do modelo norte-americano.

Na próxima seção, faço uma breve discussão sobre as críticas que alguns autores vêm fazendo à Educação Financeira. A seguir, analiso o site norte-americano My money, depois o site francês La finance pour tous e, por fim, o

3 Tendo em vista a grande quantidade de materiais produzida pelos países em questão, optou-se por restringir as análises do presente artigo ao conteúdo de sites voltados para o público em geral. Investigações futuras serão desenvolvidas para analisar as orientações relativas ao desenvolvimento da Educação Financeira no ambiente escolar, que também estão disponíveis online. 
site brasileiro Vida e dinheiro. Encerro o artigo com uma sugestão preliminar para reorientar a Educação Financeira no Brasil ${ }^{4}$.

\section{Educação Financeira como ação de uma biopolítica neoliberal}

De acordo com alguns autores, apesar de, desde o século XIX, existir campanhas voltadas para o estímulo à poupança por parte das classes populares (CLARKE, 2015), é com a consolidação da racionalidade neoliberal que houve um impulso para a implantação da Educação Financeira. Nesse sentido, para Arthur (2012, p. x), a Educação Financeira consiste em uma estratégia para aprofundar a desigualdade, entendida "como uma condição de máxima liberdade na qual cada indivíduo é livre de coerções do Estado e capaz de escolher entre opções disponíveis no mercado". Este autor coloca-se na esteira de Foucault (2008), para quem o neoliberalismo, entendido como uma forma de racionalidade política que se atravessa na produção de modos de vida ou, como ele denomina, uma governamentalidade, necessita da produção das desigualdades, porque elas fomentam a competição, que constitui seu princípio de inteligibilidade.

Ainda, segundo Arthur (2012), o neoliberalismo, ao mesmo tempo que enfraquece os mecanismos de gerenciamento coletivo do risco (aposentadorias, segurança social, saúde pública etc.), procura instrumentalizar os trabalhadores com um letramento financeiro, supondo que assim possam enfrentar individualmente os riscos e prover suas necessidades. Desse modo, entendo a Educação Financeira como uma biopolítica em que o Estado age como um conselheiro para substituir os mecanismos de proteção (SARAIVA, 2013). A Educação Financeira seria, então, um complemento às políticas de austeridade características do neoliberalismo. Arthur (2012), que denomina de Educação Financeira do consumidor este modelo individualizante que vem sendo adotado no Reino Unido, bem como na maioria dos outros países, pontua que esta prática seria um dos elementos que permite a reinterpretação da exploração da classe trabalhadora, neutralizando sua força política e minando sua capacidade de resistir e de formular alternativas ao projeto neoliberal. Acredito que a Educação Financeira pertença a um conjunto de estratégias características das sociedades de controle que visam minimizar a força política e maximizar a conformação dos sujeitos

4 As análises aqui apresentadas referem-se à configuração dos sites no primeiro quadrimestre de 2017. Cabe notar que os sites francês e norte-americano mantêm sua estrutura há, pelo menos, cinco anos. 
às condições sociais sem apelar para os rígidos regulamentos disciplinares. As estratégias atuais são mais sofisticadas do que aquelas da disciplina, sendo mais difíceis de serem percebidas e de suscitarem resistência.

Para Clarke (2015), a Educação Financeira é uma promessa vazia, tendo em vista que diversos estudos não conseguiram comprovar que o letramento financeiro efetivamente melhora as condições de vida dos indivíduos, principalmente aqueles em situações de maior vulnerabilidade, pois as competências desenvolvidas são, por diversas razões, insuficientes para garantir escolhas acertadas. Essas razões, ainda que também possuam elementos subjetivos, na maioria das vezes estão ligadas a questões que fogem ao controle individual: desemprego, baixa renda, discriminação, deficiências educacionais. A Educação Financeira seria, até mesmo, potencialmente perigosa, pois "quando os indivíduos se encontram em péssimas condições financeiras, o modelo de regulação por meio da educação culpa-os por sua situação crítica, envergonhando-os e desviando os apelos para uma efetiva regulação do mercado" (WILLIS, 2008, p. 202). O modelo individualizante de Educação Financeira do consumidor é o adotado pelo site norte-americano My money, conforme as análises que apresento na próxima seção.

\section{My money - Educação Financeira nos Estados Unidos}

Os Estados Unidos mantêm um site intitulado My money (EUA, 2017), que visa promover a Educação Financeira junto à população. A criação do site foi uma iniciativa da Comissão Federal de Letramento e Educação Financeira (FLEC), liderada pelo Secretário do Tesouro, cargo com atribuições semelhantes às de Ministro da Fazenda no Brasil. Além do Department of the Treasury, a Comissão é composta por um conjunto de outros 22 órgãos públicos, sendo apenas um deles equivalente ao Ministério da Educação. Portanto, é possível afirmar que a área educacional é coadjuvante nesse processo.

Como o próprio site enuncia na sua página intitulada My money Five, seu objetivo é ensinar os indivíduos a administrar e a fazer crescer o seu dinheiro. $\mathrm{O}$ título My money Five refere-se a cinco princípios que seriam a base da Educação Financeira, ou seja, que permitiram "obter o máximo de seu dinheiro" (EUA, 2017, não pag.): ganhar, gastar, poupar \& investir, tomar emprestado, proteger. Cada um desses princípios é discutido em uma aba específica.

Ganhar dinheiro, segundo o site, não se restringe ao que nos pagam por nosso trabalho, mas se estende a compreender como se compõe nosso contra- 
cheque, que impostos e taxas são pagos, quais os benefícios que trazem e a possibilidade de fazer abatimentos em impostos. É importante observar que ao propor uma discussão sobre o contracheque, o site sinaliza que a Educação Financeira que ele oferece está voltada para trabalhadores e não para rentistas ou empresários. Portanto, parece haver um entendimento de que o segmento populacional - que não teria habilidades em lidar com o dinheiro - seria justamente aquele que vende sua força de trabalho. A venda da força de trabalho em uma sociedade que valoriza, sobremaneira, os self made men, ou seja, os empreendedores, parece ser uma deficiência que a Educação Financeira teria a tarefa de, pelo menos em parte, compensar. Nesse sentido, o site corrobora as discussões de Clarke (2015), para quem a Educação Financeira reflete as desigualdades sociais. Segundo ele, aqueles em situação de desvantagem econômica receberão "conselhos sobre poupança, seguros, riscos associados a empréstimos para consumo" (CLARKE, 2015, p. 6), enquanto os que contam com mais recursos receberão informações sobre formas sofisticadas de investimentos.

Também é importante notar a ênfase que o site dá para o pagamento de impostos e taxas que reduzem a renda líquida, incentivando que cada um estude formas de dedução que amenizem os descontos. Aqui, é possível perceber a orientação individualista da Educação Financeira oferecida pelo My money, tendo em vista que não foi possível encontrar no site referências sobre o papel social dos impostos. Por fim, o site relaciona o princípio de ganhar dinheiro com o investimento em educação e treinamento, deixando claro que isto não estaria incluído no princípio gastar. Isso mostra de modo claro a assunção dos princípios da Escola de Chicago, a qual considera que a educação faz crescer o capital humano dos indivíduos, possibilitando aumento da renda (SCHULTZ, 1971).

Gastar dinheiro é apresentado pelo site como algo indispensável, quase um mal necessário. Gastar deve estar baseado no princípio de utilizar sabiamente o dinheiro, sendo necessário estabelecer objetivos de curto e longo prazo, bem como estratégias financeiras para alcançá-los. Os indivíduos são convocados a viver dentro de suas posses, monitorando seu orçamento e planejando suas compras. É importante notar que esse conselho vai na contramão dos modos de vida das sociedades contemporâneas, marcadas pelo alto índice de consumo. Cabe destacar, ainda, que as estratégias de marketing voltadas para a captura de consumidores são cada vez mais elaboradas, orientando para o consumo por impulso ${ }^{5}$. Portanto, entendo que aqui fica evidente a individualização da responsabilidade característica da racionalidade neoliberal.

5 De acordo com uma pesquisa de mercado realizada por uma associação de cartões de crédito nos EUA, cinco em cada seis consumidores declaram realizar compras por impulso (o que significa em torno de 83,33\% - CREDIT CARDS, 2017). Este número é semelhante ao brasileiro, 
A orientação dada pelo site está voltada para sensibilizar os indivíduos a agirem como gestores de seus impulsos e desejos, capazes de resistirem aos apelos que os cercam, o que os levaria a ter a paz concedida aos que conseguem viver sem extrapolar seus recursos e sem recair no endividamento. Dito de outro modo, as recomendações do site orientam para que cada um aceite suas limitações financeiras. Cabe destacar que "pelo consumo, nós mantemos uma relação cotidiana com a economia da dívida sem o saber" (LAZZARATO, 2011, p. 20), tendo em vista que muitas de nossas compras são realizadas com cartão de crédito. Portanto, na sociedade contemporânea, consumo e dívida andam lado a lado. Incitar a um consumo moderado significa orientar em direção não de uma vida sem dívidas, mas com dívidas pelas quais possamos nos responsabilizar.

Poupar, de acordo com o site, é importante porque "pessoas que têm o hábito de poupar regularmente, mesmo pequenas quantias, estão no caminho do sucesso" (EUA, 2017, não pag.). Ou seja, poupadores são vencedores, um rótulo identitário sumamente valorizado naquilo que Foucault (2008) chama, conforme já mencionei antes, de governamentalidade neoliberal, cujo princípio de inteligibilidade é a competição. E por que os poupadores seriam vencedores? Porque poderão usar "sua poupança para planejar os eventos da vida e para fazer frente a necessidades não planejadas e emergências" (EUA, 2017, não pag.). O sucesso passa por uma vida com metas a serem cumpridas por meio de um planejamento financeiro; ou seja, uma vida que se distancia do consumo exacerbado e por impulso. Entre os eventos da vida que serão facilitados pelo hábito da poupança, o site destaca a aposentadoria e a educação dos filhos. Cabe ainda destacar que, de acordo com o site, poupar deve ultrapassar o patamar de uma prática eventual e tornar-se um modo de vida; ou seja, uma forma de constituição de si, a produção de um ethos. Não apenas poupar, mas se tornar um poupador. Isso pode ser percebido pela afirmação de que "as pessoas que mantêm o controle de suas economias muitas vezes acabam economizando mais, porque eles têm isto em suas mentes" (EUA, 2017, não pag.).

Porém, não basta apenas poupar. É necessário investir o que for poupado, sendo recomendável ter um conselheiro financeiro qualificado para que o dinheiro poupado seja maximizado. Novamente lembramos Clarke (2015): como já mencionei anteriormente, existem indícios de que o site esteja voltado para trabalhadores, a quem se ensinariam princípios básicos para o equilíbrio financeiro, mas não formas sofisticadas de investimento. O conselheiro é uma figura de crescente destaque na contemporaneidade, identificando-se como coach, personal trainer, personal stylist ou, na sua forma genérica, como um manual

segundo pesquisa do Datafolha (FOLHA DE SÃO PAULO, 2013). Outros dados acerca do consumo por impulso nos Estados Unidos podem ser vistos em Betabait (2013). 
de autoajuda. $\mathrm{O}$ fortalecimento do conselheiro estaria em estreita relação com a emergência de uma sociedade que convoca cada um a ser empresário de si, isto é, a praticar de modo crescente o governo de si por si. Se os regulamentos rígidos da disciplina perdem força para os mecanismos de controles mais rizomáticos, os sujeitos apelam para conselheiros que os auxiliem a ter alguma segurança neste mundo de normas cambiantes.

Seguindo adiante, o site admite que algumas vezes seja necessário tomar um empréstimo. Isso pode acontecer para realizar uma aquisição mais vultosa, como um carro ou uma casa, ou para custear a educação. Evidentemente, o primeiro alerta é que se procure evitar tomar empréstimos. Porém, o site destaca que a capacidade de tomar empréstimos está relacionada com o modo como o sujeito se relaciona com a dívida. O histórico de pagamentos de contas em geral e os empréstimos são levados em conta pelo banco na concessão do crédito. De acordo com Lazzarato (2011, p. 45),

O crédito explora e solicita [...] a ação ética e o trabalho de constituição de si em nível individual e coletivo. O que é mobilizado pela relação de crédito não são as capacidades físicas e intelectuais, como no trabalho (material ou imaterial, pouco importa), mas a moralidade do devedor, seu modo de existência (seu ethos).

A questão da constituição de si, de um ethos, volta a aparecer. Entendo que aí resida o fundamento do site e do tipo de Educação Financeira que ele deseja proporcionar: a produção de um sujeito poupador e bom pagador de suas dívidas, que assumirá individualmente a responsabilidade pelo bom funcionamento de um mercado financeiro fortemente desregulamentado. Um sujeito que mantém um trabalho sobre si e uma relação consigo que o torne um elemento que promova o bom funcionamento das finanças. Conforme Agamben (2015), a racionalidade política atual considera mais produtivo controlar os efeitos do que as causas. À medida que o marketing seduz para o consumo e que o mercado oferece empréstimos exigindo garantias muito precárias, produzem-se sujeitos crescentemente endividados, colocando em risco o equilíbrio econômico nacional e mundial, como se viu na crise do subprime. A estratégia para reduzir esse risco não reside em atacar as causas, fortalecendo regulamentações, mas seus efeitos, buscando produzir sujeitos prudentes (O’MALLEY, 1996) que assumam para si a tarefa de fazer o mercado funcionar.

Por fim, o último princípio apresentado pelo site é proteger. Mas o que significa proteger? Segundo o site, "significa tomar precauções em relação a sua 
situação financeira, com destaque para a importância de se ter uma poupança para emergências e de se contratar seguros" (EUA, 2017, não pag.). De certo modo, esse princípio funciona quase como um reforço na produção do sujeito prudente que não apenas honra suas dívidas e poupa, como também se previne individualmente contra os infortúnios. Os enunciados presentes nestas páginas mostram a ruptura do mutualismo surgido na Modernidade, que visava construir sistemas de proteção coletivos, dando lugar à ação individual contemporânea (SARAIVA, 2013).

Além da discussão dos cinco princípios da educação financeira, o site apresenta links com orientações sobre como lidar com diversos eventos da vida: nascimento de um filho, ensino superior e educação continuada, casamento, divórcio, compra da casa própria, perda de emprego, aposentadoria, morte de um familiar, abertura de um negócio e eventos inesperados. Para cada um desses acontecimentos, o site mostra uma grande quantidade de links (mais de 200 para cada um) com artigos, ferramentas para simulação, vídeos e relatórios, sempre apresentando descrições sucintas na página de busca. A análise do conteúdo do site não permitiu encontrar discussões acerca do funcionamento mais amplo da economia e das finanças e dos seus efeitos sociais, em especial na produção de desigualdades. No site francês de Educação Financeira, a orientação é um pouco diferente.

\section{La finance pour tous}

Assim como os Estados Unidos, a França também mantém um site voltado para a educação financeira da população: La finance pour tous (FRANÇA, 2017). O site é uma iniciativa do Institut pour l'Education Financière du Public (IEFP), uma associação autorizada pelo Ministério da Educação Nacional, que tem o apoio de diversas instituições, sendo as principais a Autoridade dos Mercados Financeiros, a Federação Bancária Francesa, o Banco da França e o próprio Ministério da Educação Nacional. A necessidade de autorização do Ministério da Educação sinaliza um maior protagonismo da área educacional na França em relação aos Estados Unidos.

O site, que se define como o site pedagógico das finanças e do dinheiro, apresenta seus objetivos de modo muito mais detalhado do que o My money. Além disso, é possível identificar uma abrangência bem mais ampla. A educação financeira que é aí oferecida visa desenvolver conhecimentos que permitam ao usuário: "1. melhor gerir o seu dinheiro; 2. melhor compreender e escolher os 
produtos financeiros; 3 . sentir-se mais à vontade em seu ambiente cotidiano" (FRANÇA, 2017). Em relação ao terceiro ponto, o site esclarece que isto significa compreender o funcionamento de taxas de juros e seguros, mas também temas de maior amplitude, tais como: para que serve o G20 ou como se produz o lucro. Portanto, já de saída fica evidente que, ainda que boa parte do conteúdo do site esteja voltado para instrumentalizar os indivíduos a lidarem com suas finanças pessoais, realizando uma Educação Financeira nos moldes que Arthur (2012) chama de Educação Financeira do consumidor, existe, também, uma preocupação de fazer compreender os princípios da economia, o que constituiria uma Educação Financeira do cidadão, segundo o mesmo autor. Nesse sentido, é possível dizer que o site imprime uma orientação mais social à Educação Financeira, não fechando o foco apenas em responsabilidades individuais, mas permitindo que os indivíduos compreendam que estão inseridos em um contexto complexo, cujos efeitos se fazem sentir em sua vida cotidiana.

Se o site norte-americano enfatizava os cinco princípios que deveriam organizar as finanças pessoais, o site francês enfatiza oito tópicos que seriam fundamentais para a educação financeira: decriptografias, banco no cotidiano, poupança/alocação, imóveis, seguros/previdência, impostos, vida familiar/consumo, vida profissional/aposentadoria. Cada um desses tópicos constitui uma seção do site, disponibilizando um conjunto variado de artigos e ferramentas. Parece-me especialmente interessante analisar a apresentação da seção decriptografias. $\mathrm{O}$ site a anuncia do seguinte modo: "Se você tiver dúvidas sobre o funcionamento da economia, sobre as notícias financeiras ou sobre os mecanismos de alocação da poupança, você vai encontrar neste espaço informações pedagógicas, explicações sintéticas e dados-chave sobre esses temas" (FRANÇA, 2017). Esta seção, a primeira na barra do menu superior, visa aprimorar a compreensão acerca dos mecanismos econômicos por meio de artigos (algumas vezes reunidos em dossiês), infográficos e um glossário. Aí se encontra a marca de uma preocupação com uma Educação Financeira cidadã que permite aos indivíduos ampliar sua compreensão sobre os processos financeiros e econômicos.

O tema consumo aparece como um dossiê na seção decriptografias, além de ocupar o título de outra seção denominada vida familiar/consumo. Esse tema também está presente no site norte-americano, e acredito que poderá mostrar de modo mais claro a diferença de orientação entre ambos. Conforme já comentei anteriormente, o site My money não tem uma seção sobre consumo, mas sobre gastar dinheiro. Na seção gastar, o My money recomenda o máximo de moderação nos gastos, não havendo qualquer comentário sobre o significado do consumo ou a relação dos sujeitos com o consumo. As orientações são bastante mecanicistas. Inclusive, existe a sugestão de que se estabeleça um teto de despesas mensais ou semanais e que, ao atingir, não se faça mais nenhuma despesa. 
Por outro lado, o La finance pour tous, ao associar o consumo com a vida familiar, sinaliza um reconhecimento de que o consumo está associado com questões subjetivas e afetivas. Evidentemente que existem no site francês recomendações para que cada um estabeleça um orçamento pessoal, administre seus recursos e faça um planejamento financeiro, tal como no My money. Entretanto, o conteúdo é orientado por uma representação de que consumir é parte importante da vida e está ligado ao bem-estar, estando associado com eventos importantes - como a decisão de um casal em viver junto, o nascimento e a criação de filhos, a morte de um familiar - e com situações que envolvem despesas que não são de primeira necessidade, mas que tornam a vida melhor, como férias.

Nesta seção "vida familiar/consumo", o La finance pour tous apresenta uma subseção que trata de auxílios financeiros e sociais, destinadas a "pessoas em situação de fragilidade financeira, famílias com renda modesta, em situação precária ou de pobreza". Aí estão informações diversas voltadas para indivíduos que, de algum modo, estão em situação de vulnerabilidade, tais como o direito a serviços bancários para aqueles que não têm condições de terem uma conta, a possibilidade de receber auxílio para os filhos, redução nas tarifas de gás e energia, auxílio moradia, bolsas de estudo, seguro saúde, inserção em programas de renda mínima e garantias trabalhistas, como o direito a um salário mínimo. Em nenhum momento aparece no My money orientações sobre como acessar programas sociais ou políticas públicas de transferência de renda, apesar de que nos Estados Unidos também exista esse tipo de ação. Tendo em vista que este site tem uma área específica sobre como ganhar dinheiro, o fato de não haver orientações sobre como se beneficiar desses programas (e outros semelhantes) mais uma vez consolida a ideia de uma Educação Financeira voltada para a individualização de responsabilidades.

O site francês também dedica uma seção ao tema vida profissional/aposentadoria, em que trata dos direitos e deveres dos assalariados, de como avançar na carreira profissional, das possibilidades de se tornar um empreendedor, dos recursos para enfrentar o desemprego, do programa de renda mínima e dos modos como se preparar e obter a aposentadoria. O tema da aposentadoria está presente em ambos os sites e, como veremos posteriormente, também é destacado no site brasileiro. Todos os três países, cujos sites são analisados, possuem algum sistema público de aposentadorias, mas todos os três sites incentivam que sejam realizados investimentos próprios em previdência privada para a melhoria da renda. O sistema de previdência social se constitui uma preocupação atual para a maioria dos governos nacionais. Em Estados orientados pela racionalidade neoliberal, cada vez mais os indivíduos são incitados a prover por si mesmos os recursos para garantir uma velhice tranquila. 
A partir das discussões anteriores, foi possível perceber que a Educação Financeira oferecida pelo site norte-americano e pelo site francês constituem dois modelos distintos: o primeiro orientado para uma estrita adaptação dos indivíduos; o segundo, apesar de não desprezar as orientações individuais, para buscar uma instrumentalização mais ampla, visando não apenas adaptar, mas criar condições para a compreensão do funcionamento e dos efeitos das finanças. A seguir, será analisado o site brasileiro. Como veremos, seu modelo de Educação Financeira está mais próximo do My Money do que do La finance pour tous.

\section{Vida e dinheiro}

O site brasileiro de Educação Financeira é denominado Vida e dinheiro e constitui parte da Estratégia Nacional de Educação Financeira (ENEF), instituída pelo Decreto Federal 7.397/2010 (BRASIL, 2010). O objetivo da ENEF "é contribuir para o fortalecimento da cidadania ao fornecer e apoiar ações que ajudem a população a tomar decisões financeiras mais autônomas e conscientes" (BRASIL, 2017). Apesar de haver referência à cidadania, é difícil antever, a partir da análise preliminar dos menus, esta orientação no site.

Ele é administrado pela Associação de Educação Financeira (AEF), uma organização da sociedade civil de interesse público (Oscip) ${ }^{6}$ que tem como mantenedoras quatro instituições representantes do mercado financeiro: a Associação Brasileira das Entidades dos Mercados Financeiros e de Capitais (ANBIMA), a Bolsa de Valores, Mercadorias e Futuros (BM\&FBOVESPA), a Confederação Nacional das Empresas de Seguros Gerais, Previdência Privada e Vida, Saúde Suplementar e Capitalização (CNSeg) e a Federação Brasileira de Bancos (FEBRABAN). A instância responsável pelas estratégias da ENEF é o Conselho Nacional de Educação Financeira (CNEF), composto por órgãos do governo - Banco Central do Brasil, Comissão de Valores Mobiliários, Superintendência Nacional de Previdência Complementar, Superintendência de Seguros Privados, Ministério da Justiça e Cidadania, Ministério da Educação e Ministério da Fazenda - e representantes da sociedade civil - ANBIMA, BMF\&Bovespa, CNseg e FEBRABAN.

6 “Organização da Sociedade Civil de Interesse Público ou OSCIP é um título fornecido pelo Ministério da Justiça do Brasil, cuja finalidade é facilitar o aparecimento de parcerias e convênios com todos os níveis de governo e órgãos públicos (federal, estadual e municipal) e permite que doações realizadas por empresas possam ser descontadas no imposto de renda" (ALFA BRASIL, 2017). Dito de outro modo, é uma ONG reconhecida pelo Ministério da Justiça. 
As estratégias de Educação Financeira são elaboradas com a participação de instituições ligadas ao mercado, tanto no Brasil quanto nos Estados Unidos e na França. Entretanto, creio que seja importante notar que o La finance pour tous é mantido por uma associação que tem autorização concedida pelo Ministério da Educação, conferindo, conforme já comentei, certo protagonismo para a área educacional na formulação das políticas e estratégias da Educação Financeira. Acredito que isso contribua para diferenciar a orientação do site francês em relação ao norte-americano e, como veremos adiante, ao brasileiro. Os sites de Educação Financeira dos Estados Unidos e do Brasil foram construídos sem um envolvimento mais pronunciado de setores educacionais, havendo, portanto, a tendência de que funcionem como estritas ferramentas para a condução das condutas dos sujeitos no sentido de aceitar e adaptar-se ao atual capitalismo financeiro. Já o artefato francês consegue, ainda que de modo um tanto tênue, introduzir elementos que permitam uma reflexão mais ampla sobre os efeitos do capitalismo financeiro, podendo exercer outra forma de governo sobre as condutas.

O menu principal que se encontra no topo da página do site Vida e dinheiro tem links para as seguintes seções: Educação Financeira, ENEF, Programas, Ferramentas úteis, Selo ENEF. Na primeira seção, encontra-se a definição do que seja a Educação Financeira, assumindo a conceituação da OECD apresentada anteriormente. A seguir, encontra-se a justificativa da necessidade de Educação Financeira no contexto de um Brasil no ano de 2010, ano em que foi instituída a ENEF, em que muitos indivíduos migraram da classe $D$ para a classe $C$, havendo uma forte redução da pobreza no país:

\begin{abstract}
A recente ascensão econômica de milhões de brasileiros coloca o cidadão em contato com novas situações e operações financeiras pouco familiares para muitas pessoas. Somado a isso, o aumento das possibilidades de consumo torna necessário promover a educação financeira para despertar a consciência da população quanto às suas decisões individuais e familiares relacionadas a seus recursos (BRASIL, 2017).
\end{abstract}

Analisando o excerto acima, é possível identificar que as estratégias de Educação Financeira no âmbito da ENEF estão voltadas para governar ações individuais, visando produzir sujeitos capazes de uma boa adaptação ao capitalismo financeiro. Ainda nesta página, consta que "adotar decisões de crédito, investimento, proteção, consumo e planejamento que proporcionem uma vida financeira mais sustentável gera impactos não só na vida de cada um, como 
também no futuro do nosso país", reforçando a ideia de que o funcionamento do mercado e do país dependem das opções individuais.

Na seção Ferramentas úteis estão os elementos para a Educação Financeira online. Segundo o site, as ferramentas "vão ajudar a gerir melhor o seu dinheiro e planejar o futuro" (BRASIL, 2017). As ferramentas estão agrupadas em oito seções: planejamento, poupança, crédito, seguros, investimento, consumo, direitos e deveres, previdência. Observa-se que haveria seis elementos para organizar a vida financeira (planejamento, poupança, crédito, seguros, investimento e consumo), uma seção sobre os direitos e deveres e um evento, a aposentadoria, que gera a seção "Previdência". Esta seção poderia estar integrada à poupança, a seguros e a planejamento, porém, ao optar por dar-lhe destaque, já é possível perceber que este tema é especialmente importante.

Conforme já enfatizei na seção anterior, a preocupação em estimular ações individuais para garantir renda na velhice tem sido preocupação de muitos governos. A seção "Previdência" do site está direcionada, justamente, para estimular a utilização de planos de previdência complementar, também conhecida como previdência privada, como se evidencia na afirmativa que consta na página inicial desta seção: "pensar na aposentadoria desde cedo é essencial, especialmente se você fizer a opção por um plano de previdência complementar, pois assim os valores a serem pagos serão menores e haverá mais tempo para formar as reservas de sua renda futura" (BRASIL, 2017).

Apesar dos elementos que fundamentariam a Educação Financeira no site brasileiro serem diferentes daqueles apresentados no My money, considero que o funcionamento é semelhante: seis fundamentos, cada um com uma página própria, que apresentam informações básicas e links para textos e aplicativos. Os conteúdos estão todos diretamente associados com escolhas e ações individuais, sem traços de uma preocupação em introduzir os sujeitos em problematizações mais amplas sobre as finanças e o funcionamento do mercado. De modo geral, é possível concluir que a Educação Financeira desenvolvida por meio do site Vida e dinheiro é uma Educação Financeira de consumidores, como indica Arthur (2012), com uma orientação muito semelhante ao My money. Tendo em vista as discussões já realizadas neste artigo, considero recomendável rever esse modelo, de modo a proporcionar aos usuários informações mais abrangentes sobre economia e finanças, tal como o faz o site La finance pour tous, para que possam se posicionar criticamente, conforme sugiro na próxima seção. 


\section{Da Educação Financeira para a educação em economia da dívida}

De acordo com Lazzarato (2011, p. 13), para compreender e analisar adequadamente a configuração do capitalismo atual não se deve focar "nas finanças, mas na economia da dívida que a compreende e a transborda, assim como sua política de assujeitamento". Arthur (2012, p. xiii) "argumenta que ter um letramento financeiro deve compreender mais do que a habilidade de entender a diferença entre taxas de juros real e nominal ou como os juros compostos funcionam". Ainda que habilidades financeiras possam dar alguma contribuição para o bem-estar pessoal, o letramento financeiro deve fazer com que

entendamos nossa responsabilidade pelo risco econômico criado socialmente, de modo que possamos agir com responsabilidade e tornarmo-nos responsáveis pelos efeitos de nossas ações coletivas como consumidores e como produtores [...]. Estes efeitos ultrapassam a atual crise financeira e incluem efeitos que também estão presentes em tempos de crescimento (desemprego estrutural, pobreza, expectativa de vida encurtada, fome,...) e que requerem, ao invés de respostas individuais, respostas coletivas (ARTHUR, 2012, p. xiii-xiv).

Desse modo, gostaria de finalizar este artigo justamente com a sugestão de que a Educação Financeira no Brasil passe a ser reapropriada pelo campo educacional, deslocando o protagonismo das instituições financeiras. Com isso, acredito que seria possível reorientar o site Vida e dinheiro fazendo um deslocamento capaz de torná-la uma Educação Financeira de cidadãos ou, melhor ainda, para torná-la uma Educação em economia da dívida, seguindo os conceitos de Lazzarato (2011), que promoveria um senso crítico em relação ao funcionamento do mundo contemporâneo. No momento em que as finanças têm importância crescente no capitalismo, entender esses processos é parte fundamental para a participação política. 


\section{REFERÊNCIAS}

AGAMBEN, G. Uma cidadania reduzida a dados biométricos: como a obsessão securitária faz mudar a democracia. In: GLOECKNER, R.; FRANÇA, L.; RIGON, B. Biopoliticas: estudos sobre política, governamentalidade e violência. Curitiba: iEA, 2015. p. 125-134.

ALFA BRASIL. O que é OSCIP. Disponível em: $<$ http://alfabrasil.org.br/oscip $>$. Acesso em: 17 maio 2017.

ARTHUR, C. Financial literacy education: neoliberalism, the consumer and the citizen. Rotterdam: Sense, 2012.

BETABAIT. The impulse shopping fact sheet. [22 dez. 2013]. Disponível em: <http:// betabait.com/the-impulse-shopping-fact-sheet/>. Acesso em: 17 maio 2017.

BRASIL. Estratégia Nacional de Educação Financeira - ENEF. Vida e dinheiro. Disponível em: <http://www.vidaedinheiro.gov.br/>. Acesso em: 17 maio 2017.

BRASIL. Decreto $n^{\circ} 7.397$, de 22 de dezembro de 2010. Institui a Estratégia Nacional de Educação Financeira - ENEF, dispõe sobre a sua gestão e dá outras providências. Disponível em: <http:/www.planalto.gov.br/ccivil_03/_ato2007-2010/2010/decreto/ d7397.htm>. Acesso em: 17 maio 2017.

CLARKE, C. Learning to fail: resilience and the empty promise of financial literacy education. Consumption Markets \& Culture, v. 18, p. 1-20, mar. 2015.

CREDIT CARDS. Survey: 5 in 6 Americans admit to impulse buys. Disponível em: $<$ http://www.creditcards.com/credit-card-news/impulse-buy-survey.php\#>. Acesso em: 17 maio 2017.

EUA. Financial Literacy and Education Commission - FLEC. My money. Não paginado. Disponível em: <https://www.mymoney.gov>. Acesso em: 17 maio 2017.

FOLHA DE SÃO PAULO. 85\% dos brasileiros fazem compras por impulso, revela pesquisa do SPC. [27 fev. 2013]. Mercado. Disponível em: <http://www1.folha.uol.com.br/ mercado/2013/02/1237661-85-dos-brasileiros-faz-compras-por-impulso-revela-pesquisa-do-spc.shtml>. Acesso em: 17 maio 2017.

FOUCAULT, M. Nascimento da biopolitica. São Paulo: Martins Fontes, 2008.

FRANÇA. Institut pour l'Education Financière du Public - IEFP. La finance pour tous. Disponível em: <http://www.lafinancepourtous.com/>. Acesso em: 17 maio 2017.

INFE. International Gateway to Financial Education. Disponível em <http://www. financial-education.org/join_INFE.html>. Acesso em: 17 maio 2017.

LAZZARATO, M. La fabrique de l'homme endetté. Paris: Amsterdam, 2011. 
O'MALLEY, P. Risk and responsibility. In: BARRY, A.; OSBORNE, T.; ROSE, N. Foucault and political reason. Chicago: Universidade de Chicago, 1996.

OECD. National Strategies for Financial Education. Disponível em: $<$ http://www.oecd. org/daf/fin/financial-education/nationalstrategiesforfinancialeducation.htm $>$. Acesso em: 17 maio 2017a.

OECD. What is PISA? Disponível em: <http://www.oecd.org/pisa/aboutpisa/>. Acesso em: 17 maio $2017 \mathrm{~b}$.

OECD. PISA 2012 - Assessment and Analytical Framework. Paris: OECD, 2013. Disponível em: $<$ https://www.oecd.org/pisa/pisaproducts/PISA\%202012\%20framework\%20 e-book_final.pdf $>$. Acesso em: 17 maio 2017.

OECD. Improving Financial Literacy: Analysis of Issues and Policies. [10 nov. 2005]. Disponível em: $<\mathrm{http}$ ://www.oecd.org/finance/financial-education/improvingfinancialliteracyanalysisofissuesandpolicies.htm>. Acesso em: 17 maio 2017.

SARAIVA, K. Educando para viver sem riscos. Educação, Porto Alegre, v. 36, n. 2, p.168-179, maio-ago. 2013.

SCHULTZ, T. W. O capital humano. Rio de Janeiro: Zahar, 1971.

WIKIPEDIA. Crise do subprime. Disponível em: <https://pt.wikipedia.org/wiki/Crise do subprime>. Acesso em: 17 maio 2017.

WILLIS, L. E. Against Financial-Literacy Education. Iowa Law Review, v. 94, p. 197285,2008 .

Texto recebido em 11 de julho de 2017. Texto aprovado em $1^{\circ}$ de agosto de 2017. 
